\title{
Identification of Predictive CT Angiographic Factors in the Develop- ment of High-Risk Type 2 Endoleaks after Endovascular Aneurysm Repair in Patients with Infrarenal Aortic Aneurysms
}

\author{
Identifikation prädiktiver CT-angiographischer Faktoren für die Entstehung \\ eines Hochrisiko Typ-2 Endoleaks nach endovaskulärem Aortenrepair bei Pa- \\ tienten mit infrarenalen Bauchaortenaneurysmen
}

Authors

Affiliations

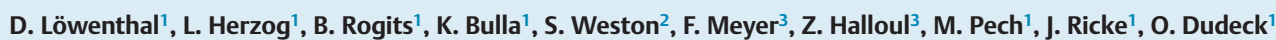

Radiology and Nuclear Medicine, University Magdeburg

Biometry and Medical Informatics, University Magdeburg

3 General, Visceral and Vascular Surgery, University Magdeburg
Key words

- aorta

- CT angiography

- aneurysm

received 27.11.2013

accepted 11.7.2014

Bibliography

DOI http://dx.doi.org/

10.1055/s-0034-1385123

Published online: 16.9.2014

Fortschr Röntgenstr 2015; 187:

49-55 @ Georg Thieme Verlag

KG Stuttgart · New York ·

ISSN 1438-9029

\section{Correspondence}

\section{Dr. David Löwenthal}

Klinik für Radiologie und

Nuklearmedizin,

Universitätsklinikum

Magdeburg

Leipzigerstr 44

39120 Magdeburg

Germany

Tel.: ++ 49/3 91/6713030

Fax: ++ 49/3 91/6713029

david.loewenthal@googlemail. com

\section{Abstract \\ $\nabla$}

Purpose: An extensive analysis of the value of computed tomography (CT) parameters as potential predictors of the clinical outcome of type 2 endoleaks after endovascular aortic aneurysm repair (EVAR).

Materials and Methods: Initial CT scans of 130 patients with abdominal aortic aneurysms (AAAs) were retrospectively reviewed. On the basis of postoperative CT scans and angiographies, patients were stratified into a low-risk group (LRG; without or transient type 2 endoleak; $n=80$ ) and a high-risk group (HRG, persistent type 2 endoleak or need for reintervention; $\mathrm{n}=50$ ). Statistical analysis comprised a univariate and multivariate analysis.

Results: Anatomical, thrombus-specific, as well as aortic side branch parameters were assessed on the initial CT scan. Of all anatomical parameters, the diameter of the immediate infrarenal aorta was significantly different in the univariate analysis (LRG $22.4 \pm 3.8 \mathrm{~mm}$; HRG $23.6 \pm 2.5 \mathrm{~mm} ; \mathrm{p}=0.03)$. The investigation of the thrombus-specific parameters showed a trend towards statistical significance for the relative thrombus load (LRG $31.7 \pm 18.0 \%$; HRG $25.3 \pm 17.5 \%$; $=0.09$ ). Assessment of aortic side branches revealed only for the univariate analysis significant differences in the patency of the inferior mesenteric artery (LRG 71.3\%; HRG 92.0\%; $\mathrm{p}=0.003$ ) and their diameter (LRG 3.3 $\pm 0.7 \mathrm{~mm}$; HRG $3.8 \pm 0.9 \mathrm{~mm} ; \mathrm{p}=0.004)$. In contrast, the number of lumbar arteries (LAs; LRG 2.7 \pm 1.4 ; HRG 3.6 \pm 1.2 ; univariate: $\mathrm{p}=0.01$; multivariate: $\mathrm{p}=0.006$ ) as well as their diameter (LRG $2.1 \pm 0.4 \mathrm{~mm}$; HRG 2.4 $\pm 0.4 \mathrm{~mm}$; univariate: $\mathrm{p}<0.001$; multivariate: $\mathrm{p}=0.006$ ) were highly significantly associated with the development of type 2 endoleaks of the HRG.
Conclusion: The most important predictive factors for the development of high-risk type 2 endoleaks were mainly the number and the diameter of the LAs which perfused the AAA. Key Points:

- This study is a very detailed and comprehensive analysis of the value of various CT parameters as potential predictors of the clinical outcome of type 2 endoleaks after EVAR.

- Anatomical as well as thrombus-specific parameters were unsuitable as predictors.

- The most important predictive factors were mainly the number and the diameter of the LAs which perfused the AAA.

Citation Format:

- Löwenthal D., Herzog L., Rogits B. etal. Identification of Predictive CT Angiographic Factors in the Development of High-Risk Type 2 Endoleaks after Endovascular Aneurysm Repair in Patients with Infrarenal Aortic Aneurysms. Fortschr Röntgenstr 2015; 187: 49-55

\section{Zusammenfassung \\ $\nabla$}

Ziel: Eine umfängliche Analyse zur Wertigkeit computertomografischer (CT) Parameter als potenzielle Prädiktoren des klinischen Verlaufs von Typ-2 Endoleaks nach endovaskulärem Aortenrepair (EVAR).

Material und Methoden: Retrospektiv wurden die präoperativen CT-Angiografien von 130 Patienten mit einem infrarenalen Bauchaortenaneurysma (BAA) ausgewertet. Anhand postoperativer CT und angiografischer Verlaufskontrollen wurden die Patienten einer Niedrigrisikogruppe (NRG; ohne bzw. mit transientem Typ-2 Endoleak; $\mathrm{n}=80$ ) oder einer Hochrisikogruppe (HRG; mit persistentem bzw. behandlungsbedürftigem Typ2 Endoleak; $n=50$ ) zugeordnet. Die statistische 
Auswertung umfasste eine univariate und multivariate Analyse. Ergebnisse: Anhand der initialen CT wurden anatomische, thrombusspezifische und Parameter zu aortalen Seitästen beurteilt. Bei den anatomischen Parametern fand sich lediglich für den Durchmesser der unmittelbar infrarenalen Aorta ein signifikanter Unterschied in der univariaten Analyse (NRG 22,4 $\pm 3,8 \mathrm{~mm}$; HRG 23,6 $\pm 2,5 \mathrm{~mm} ; \mathrm{p}=0,03$ ). Die Betrachtung thrombusspezifischen Parameter zeigte für die relative Thrombusfläche

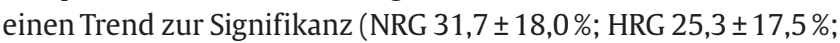
$\mathrm{p}=0,09$ ). Hinsichtlich der aortalen Seitäste waren die Offenheit der Arteria mesenterica inferior (NRG 71,3\%; HRG 92,0\%; $\mathrm{p}=0,003$ ) und deren Durchmesser (NRG 3,3 $\pm 0,7 \mathrm{~mm}$; HRG 3,8 $\pm 0,9 \mathrm{~mm} ; \mathrm{p}=0,004)$ lediglich univariat signifikant unterschiedlich. Demgegenüber waren sowohl Anzahl der Lumbalarterien (LA; NRG 2,7 $\pm 1,4$; HRG 3,6 $\pm 1,2$; univariat: $\mathrm{p}=0,01$; multivariat: $\mathrm{p}=0,006$ ) sowie deren Durchmesser (NRG 2,1 $\pm 0,4 \mathrm{~mm}$; HRG 2,4 $\pm 0,4 \mathrm{~mm}$; univariat: $\mathrm{p}<0,001$; multivariat: $\mathrm{p}=0,006)$ hochsignifikant mit der Entstehung eines Hochrisikotyp-2 Endoleaks assoziiert.

Schlussfolgerung: Als bedeutendste prädiktive Faktoren für die Entstehung eines Hochrisikotyp-2 Endoleaks fanden sich die Anzahl als auch der Durchmesser der perfundierten aneurysmaspeisenden LA.

\section{Introduction}

$\nabla$

Since the first description by Parodi et al., endovascular aortic aneurysm repair (EVAR) of infrarenal abdominal aortic aneurysms (AAAs) has become established as an accepted alternative to open surgery $[1,2]$. An inherent problem of the technique is the development of endoleaks due to persistent, postinterventional perfusion of the aneurysmal sac $[3,4]$. With $20-30 \%$, type 2 endoleaks comprise the majority of endoleaks [5]. This is caused by a retrograde flow via the lumbar arteries (LAs), inferior mesenteric artery (IMA), or other aortic collaterals [3]. Type 2 endoleaks are usually only transient and thrombose spontaneously within the first 6 months in up to $80 \%$ of cases $[3,6]$. On the other hand, type 2 endoleaks that persist longer than 6 months are associated with a higher probability of a complicated course and risk of aneurysm rupture due to an intrasacular increase in pressure [5-11]. This increase in the size of the aneurysmal sac is observed significantly more often in patients with a persistent type 2 endoleak (24-52\%) than in patients without a type 2 endoleak $(13 \%)[5,6]$.

In the follow-up of patients after EVAR, increase in the size of the aneurysmal sac is a generally accepted criterion for reintervention [12]. On the other hand, the treatment of type 2 endoleaks without changes in the aneurysmal sac is controversial $[4,8,13-15]$. While some authors are in favor of an aggressive approach particularly due to the high reintervention rate in persistent type 2 endoleaks $[8,13,15]$, other authors advocate a conservative strategy due to the low probability of aneurysm rupture $[4,14]$.

It would be of extreme clinical relevance to be able to identify a high-risk group for the development of a type 2 endoleak that is persistent or requires treatment on the basis of the initial computed tomography (CT) scan. Preoperative embolization of aortic side branches could then be performed in these patients to counteract the development of a type 2 endoleak $[16,17]$. The size of the intra-aneurys- matic thrombus volume $[18,19]$ and the number of aortic side branches [20-22] on the basis of the initial CT scan were identified as prognostic factors in previous studies. Since such parameters can affect one another, the goal of this study was to perform a comprehensive analysis of all factors previously identified as potentially predictive on the basis of preoperative CT in order to predict the clinical course of type 2 endoleaks after EVAR.

\section{Materials and Methods}

\section{Study criteria}

From December 2004 to December 2011, 161 patients were treated via EVAR for AAA. Patients without a corresponding preoperative CT scan (time between CT and implantation $>1$ month; $\mathrm{n}=7$ ) or a lack of long-term follow-up ( $<12$ months, $n=14$ ) were excluded. In addition, patients with a covered ruptured AAA $(n=4)$ were also excluded. All available postoperative examinations, CT and angiography, were used for reliable classification of the endoleak type. The relationship between periprosthetic contrast accumulation and the aortic side branches and the AAA was decisive. An association of the endoleak with LAs or the IMA was a reason for the classification as a type 2 endoleak. In the case of contrast accumulation around the ends of the prosthesis, a type 1 endoleak $(n=5)$ was suspected. Contrast accumulation around the connection between the main body and limb of the prosthesis was seen in one patient and a type 3 endoleak was suspected. Angiographies were available for further clarification in all patients with suspicion of a type 1 or type 3 endoleak and confirmed these assumptions. These patients were excluded from further analysis.

\section{Patient data}

Under consideration of the inclusion and exclusion criteria, 130 patients could be included in the study (121 men; 9 women; average age 71.9 years; 48 - 88 years). The evaluation of this patient data was approved by the local ethics committee. An Excluder prosthesis (W.L Gore \& Associates, Flagstaff, USA) was implanted in the majority of patients $(\mathrm{n}=99 ; 76 \%$ ). The remaining 31 patients received the following prosthesis types: Anaconda (Vascutek Inc., Terumo Company, Scotland; $\mathrm{n}=15 ; 12 \%$ ), Endurant (Medtronic, Inc., Minneapolis, USA; $\mathrm{n}=12 ; 9 \%$ ), Zenith (Cook Medical Bloomington, USA; $\mathrm{n}=3 ; 2 \%$ ), Talent (Medtronic Vascular, Santa Rosa, USA; $\mathrm{n}=1 ; 1 \%$ ).

\section{CT protocol}

The CT protocol included a two-phase technique with reconstructed slice thicknesses of 5 and $1 \mathrm{~mm}, 120 \mathrm{kV}$ and modulated mA (Aquillion 16 rows; Toshiba Medical Systems, Netherlands). Iodinated contrast agent (80-100 ml; Imeron 300 Altana, Germany) was injected at a rate of $4 \mathrm{ml} / \mathrm{s}$ followed by $30 \mathrm{ml}$ of a saline solution. The arterial phase started in the "sure start" mode followed by the venous phase after a delay of $70 \mathrm{~s}$.

\section{Data evaluation}

After the evaluation of all available follow-ups (average length of the observation period after EVAR: 22 months; 12-64 months), the patients were assigned to either a 
low-risk group (LRG) or a high-risk group (HRG). Patients without an endoleak $(n=68)$ and with only a transient type 2 endoleak not requiring treatment (endoleak stopped within 6 months; $n=12$ ) were assigned to the LRG $(n=80)$, while patients with an endoleak that was persistent (endoleak lasting $>6$ months) or required treatment were assigned to the HRG $(n=50)$. As a rule, the indication to treat a type 2 endoleak was determined on an interdisciplinary basis at the local vascular center with a progressive increase in the size of the aneurysmal sac of $>5 \mathrm{~mm}$ compared to the preoperative measurement being viewed as a decisive criterion.

The preoperative $\mathrm{CT}$ examinations were evaluated without knowledge of the follow-ups and clinical data in consensus by 2 radiologists (D.L. and O.D.) and a vascular surgeon (Z. H.) using a PACS console (software: Infinitt ${ }^{\circledR}$, Seoul, Korea). In addition to axial slices, multiplanar reconstructions were also taken into consideration. The following parameters were organized thematically and evaluated:

- General anatomical variables. The diameter of the directly infrarenal aorta, the length of the AAA, the maximum axial diameter of the AAA and the perfused lumen, and the surface area in the region of the maximum axial diameter were determined.

- Intra-aneurysmatic thrombus parameter. This evaluation included the determination of the absolute thrombus surface area in the region of the maximum extension of the AAA and the relative percentual thrombus surface area calculated as the ratio of the thrombus surface area to the surface area of the aortic lumen according to the following formula [19]:

thrombus surface area \% = $\frac{\text { surface area of the aortic aneurysm - surface area of the aneurysm lumen }}{\text { surface area of the aortic aneurysm }}$

In addition, the maximum thickness of the thrombus within the AAA and in the branch area of the IMA and the LAs within the AAA was also documented.

- Aortic side branches. The patency and the diameter of the IMA and the number and diameter of the perfused LAs inside and outside of the AAA were determined.

The data were the basis of a complex statistical analysis using SPSS software version 21.0 (SPSS, Statistical Package for the Social Science, Chicago, IL) for Windows (Microsoft, Redmond, WA). Metric variables of both groups were compared via T-test and categorical variables via Fisher's exact test (univariate analysis). A linear logistic regression analysis (multivariate analysis) of the potentially most predictive univariate variables was performed for further evaluation. In a subsequent ROC (receiver operating characteristic) curve analysis (AUC), the significant multivariate variables were evaluated with respect to their prediction accuracy regarding the development of a high-risk type 2 endoleak and the suitable limiting value was determined via the Youden index ( $\mathrm{YI}=$ sensitivity + specificity -1 ). A p-value of $<0.05$ was viewed as a statistically significant difference.

\section{Results \\ $\nabla$}

80 of a total of 130 patients were assigned to the LRG $(61.5 \%)$. No endoleak was detected postoperatively or on all additional follow-up CT scans in 68 of these patients $(52.3 \%)$. A transient type 2 endoleak was found in 12 patients (9.2\%). 50 patients (38.5\%) were assigned to the HRG. This group was comprised of 35 patients (26.9\%) with a persistent type 2 endoleak and 15 patients (11.5\%) with a type 2 endoleak requiring treatment.

The univariate analysis of the morphological parameters yielded a significant difference in the diameter of the directly infrarenal aorta with $22.4 \pm 3.8 \mathrm{~mm}$ in the LRG and $23.6 \pm 2.5 \mathrm{~mm}$ in the HRG $(p=0.03)$. The multivariate analysis showed only a tendency toward statistical significance $(p=0.06)$. There were no differences between the two risk groups with respect to the length (LRG $64.2 \pm 25.0 \mathrm{~mm}$; HRG $68.0 \pm 21.0 \mathrm{~mm} ; \mathrm{p}=0.3$ ), diameter (LRG $54.3 \pm 14.1 \mathrm{~mm}$; HRG $56.4 \pm 11.9 \mathrm{~mm}$; $\mathrm{p}=0.3$ ) and surface area (LRG $22.2 \pm 12.5 \mathrm{~cm}^{2}$; HRG $23.4 \pm 10.3 \mathrm{~cm}^{2}$; $\mathrm{p}=0.5$ ) of the AAA. The diameter and the surface area of the perfused aneurysm lumen did not show any significant differences (see $\bullet$ Table 1 ).

The evaluation of thrombus-specific parameters also did not show any significant differences between the two groups with respect to the absolute thrombus surface area (LRG $11.1 \pm 10.6 \mathrm{~cm}^{2}$; HRG $9.3 \pm 9.0 \mathrm{~cm}^{2} ; \mathrm{p}=0.4$ ), the relative thrombus surface area (LRG $31.7 \pm 18.0 \% ; 25.3 \pm 17.5 \%$; $\mathrm{p}=0.09$ ), and the maximum thrombus thickness (LRG 18.3 $\pm 13.1 \mathrm{~mm}$; HRG $14.6 \pm 11.3 \mathrm{~mm} ; \mathrm{p}=0.2$ ). Moreover, the thrombus thickness in the branch area of the IMA (LRG 4.3 $\pm 7.5 \mathrm{~mm}$; HRG $3.1 \pm 7.4 \mathrm{~mm} ; \mathrm{p}=0.5)$ and in the branch area of the LAs within the AAA (LRG $3.1 \pm 5.2 \mathrm{~mm}$; HRG 2.7 $\pm 4.9 \mathrm{~mm} ; \mathrm{p}=0.8$ ) did not yield a significant difference between the two risk groups (see $\bullet$ Table 2).

The analysis of the number and size of aortic side branches showed that the presence of a perfused IMA is significant as a predictive factor for the development of a type 2 endoleak of the HRG according to univariate criteria $(n=57 ; 71.3 \%$ in the LRG compared to $n=46 ; 92.0 \%$ in the HRG; $p=0.003$; see - Table 3). This connection could not be confirmed in the multivariate analysis $(\mathrm{p}=0.2)$. The same is true for the average diameter of the IMA that was significantly different in the univariate analysis $(3.3 \pm 0.7 \mathrm{~mm}$ in the LRG versus 3.8

\begin{tabular}{|c|c|c|c|c|}
\hline parameter & $\begin{array}{l}\text { LRG } \\
(n=80)\end{array}$ & $\begin{array}{l}\text { HRG } \\
(n=50)\end{array}$ & $\begin{array}{l}\mathbf{P} \\
\text { (univariate) }\end{array}$ & $\begin{array}{l}\text { P } \\
\text { (multivariate) }\end{array}$ \\
\hline diameter of the directly infrarenal aorta $(\mathrm{mm})$ & $22.4 \pm 3.8$ & $23.6 \pm 2.5$ & 0.03 & 0.06 \\
\hline AAA length (mm) & $64.2 \pm 25.0$ & $68.0 \pm 21.0$ & 0.3 & n.e. \\
\hline AAA diameter $(\mathrm{mm})$ & $54.3 \pm 14.1$ & $56.4 \pm 11.9$ & 0.3 & n.e. \\
\hline AAA surface area $\left(\mathrm{cm}^{2}\right)$ & $22.2 \pm 12.5$ & $23.4 \pm 10.3$ & 0.5 & n.e. \\
\hline diameter of the perfused aneurysm lumen (mm) & $40.0 \pm 10.4$ & $43.4 \pm 12.7$ & 0.1 & 0.6 \\
\hline surface area of the perfused aneurysm lumen $\left(\mathrm{cm}^{2}\right)$ & $11.1 \pm 7.0$ & $14.2 \pm 9.9$ & 0.08 & 0.5 \\
\hline
\end{tabular}

Table 1 Anatomical parameters of the low-risk group (LRG) and high-risk group (HRG) for the development of a type 2 endoleak after EVAR.

AAA: Abdominal aortic aneurysm; n. e.: not evaluated. 


\begin{tabular}{|lllll|}
\hline parameter & $\begin{array}{l}\text { LRG } \\
(\mathbf{n = 8 0 )}\end{array}$ & $\begin{array}{l}\text { HRG } \\
(\mathbf{n = 5 0 )}\end{array}$ & $\begin{array}{l}\mathbf{P} \\
\text { (univariate) }\end{array}$ & $\begin{array}{l}\mathbf{P} \\
\text { (multivariate) }\end{array}$ \\
\hline absolute thrombus surface area $\left(\mathrm{cm}^{2}\right)$ & $11.1 \pm 10.6$ & $9.3 \pm 9.0$ & 0.4 & n.e. \\
\hline relative thrombus surface area $(\%)$ & $31.7 \pm 18.0$ & $25.3 \pm 17.5$ & 0.09 & 0.7 \\
\hline maximum thrombus thickness $(\mathrm{mm})$ & $18.3 \pm 13.1$ & $14.6 \pm 11.3$ & 0.2 & n.e. \\
\hline thrombus thickness in the branch area of the IMA $(\mathrm{mm})$ & $4.3 \pm 7.5$ & $3.1 \pm 7.4$ & 0.5 & n.e. \\
\hline thrombus thickness in the branch area of the LAs $(\mathrm{mm})$ & $3.1 \pm 5.2$ & $2.7 \pm 4.9$ & 0.8 & n.e.
\end{tabular}

Table 2 Thrombus-specific parameters of the low-risk group (LRG) and high-risk group (HRG) for the development of a type 2 endoleak after EVAR.

\begin{tabular}{|c|c|c|c|c|}
\hline parameter & $\begin{array}{l}\text { LRG } \\
(n=80)\end{array}$ & $\begin{array}{l}\text { HRG } \\
(n=50)\end{array}$ & $\begin{array}{l}\text { P } \\
\text { (univariate) }\end{array}$ & $\begin{array}{l}\text { P } \\
\text { (multivariate) }\end{array}$ \\
\hline patency of the IMA (\%) & 71.3 & 92.0 & 0.003 & 0.2 \\
\hline diameter of the IMA (mm) & $3.3 \pm 0.7$ & $3.8 \pm 0.9$ & 0.004 & 0.1 \\
\hline number of LAs outside the AAA & $2.6 \pm 1.4$ & $1.9 \pm 1.5$ & 0.04 & 0.6 \\
\hline diameter of the LAs outside the AAA (mm) & $2.2 \pm 0.3$ & $2.1 \pm 0.4$ & 0.6 & n.e. \\
\hline number of LAs within the AAA & $2.7 \pm 1.4$ & $3.6 \pm 1.2$ & 0.01 & 0.006 \\
\hline diameter of the LAs within the AAA ( $\mathrm{mm}$ ) & $2.1 \pm 0.4$ & $2.4 \pm 0.4$ & $<0.001$ & 0.006 \\
\hline
\end{tabular}

Table 3 Aortic side branches of the low-risk group (LRG) and highrisk group (HRG) for the development of a type 2 endoleak after EVAR

Average diameter in mm; light gray - high-risk type 2 endoleak improbable, dark gray - high-risk type 2 endoleak probable; limiting value: 0.45 (sensitivity of 0.71 ; specificity of 0.66 ; positive predictive value 0.57 ; negative predictive value 0.78 ).

$\pm 0.9 \mathrm{~mm}$ in the HRG; $\mathrm{p}=0.004)$. However, the significance level was again not reached in the multivariate analysis $(\mathrm{p}=0.1$; see $\bigcirc$ Table 3$)$. The average number of LAs outside the AAA also only showed significant univariate differences between the two groups (LRG $2.6 \pm 1.4 \mathrm{~mm}$; HRG 1.9 $\pm 1.5 \mathrm{~mm}$; univariate: $\mathrm{p}=0.04$; multivariate: $\mathrm{p}=0.6$; see - Table 3). In contrast, the average number of LAs within the AAA, i.e., the lumbar vessels supplying the aneurysm, was significantly different in both groups in both the univariate and multivariate analysis (LRG 2.7 $\pm 1.4 \mathrm{~mm}$; HRG $3.6 \pm 1.2 \mathrm{~mm}$; univariate: $\mathrm{p}=0.01$; multivariate: $\mathrm{p}=0.006$ ). This was also true for the average diameter of the LAs (LRG
$2.1 \pm 0.4 \mathrm{~mm} ; 2.4 \pm 0.4 \mathrm{~mm}$; univariate: $p<0.001$; multivariate: $p=0.006$; see $\bullet$ Table 3 ).

As a result, of all examined parameters, only the number and average diameter of the LAs within the AAA were suitable as predictive factors for the development of a high-risk type 2 endoleak. An ROC curve analysis that yielded an area under the curve (AUC) of 0.73 (95\% confidence interval $0.64-0.82$ ) and a limiting value (Youden index) of 0.45 (sensitivity of 0.71 and a specificity of 0.66 ; positive predictive value of 0.57 ; negative predictive value of 0.78 ) was performed to define threshold values for these two parameters that mutually affect one another (see Table 4). 


\section{Discussion}

\section{$\nabla$}

The development of an endoleak following EVAR remains an inherent problem of the technique [6]. While type 1 and type 3 endoleaks should undergo immediate reintervention, the treatment of type 2 endoleaks continues to be controversial $[3,5,6,8,14,23-27]$. Type 2 endoleaks have a high rate of spontaneous thrombosis of up to $80 \%$ so that a conservative approach is favored by some authors $[3,26]$, while persistent type 2 endoleaks are often associated with an increase in the aneurysmal sac over time and thus require reintervention [6, 27]. Based on these studies, it seems useful to differentiate between type 2 endoleaks that are benign, i. e., transient, and those that are malignant, i. e. persistent and in need of treatment. In light of this, patients were categorized into an LRG and an HRG in this study to be able to identify predictive factors associated with the development of a type 2 endoleak in the HRG on the basis of the preoperative CT scan.

Diverse morphological-anatomical parameters of the AAA, the influence of the intra-aneurysmal thrombus mass, and the number and diameter of aortic side branches were evaluated here. With respect to the morphological parameters, only the diameter of the directly infrarenal aorta differs significantly between the two groups in the univariate analysis $(p=0.03)$. Interestingly, this observation coincides with the results of another workgroup [20]. Additional morphological parameters, such as the length, diameter, and surface area of the AAA and of the perfused aneurysm lumen, did not differ between the two groups. These results corresponded with those of other authors [6, 18, 28, 29]. Therefore, Higashura et al. were able to show in a prospective study on the basis of 273 patients that both the diameter of the AAA with an average of $56 \mathrm{~mm}$ (range: $40-93 \mathrm{~mm}$ ) and the length of the aneurysm neck have no relevant effect on the development of a persistent type 2 endoleak [28]. In summary, no morphological parameter of the AAA proved suitable in this study as a predictive factor for the development of a type 2 endoleak in the HRG.

In a previous analysis of 100 patients, a connection between the size of the intra-aneurysmatic thrombus on the preoperative CT scan and the regression of the size of the aneurysmal sac over time after EVAR was able to be created [19]. In dependence on this study, we also determined a relative thrombus surface area. However, the differences between the LRG (31.7 $\pm 18.0 \%)$ and the HRG $(25.3 \pm 17.5 \%)$ showed only a trend toward significance $(\mathrm{p}=0.09)$. Moreover, there were no significant differences regarding the absolute thrombus surface area in the aneurysmal sac and the maximum thrombus thickness. These results coincided with those of Abu Rhama et al. who also found no correlation between the maximum thrombus thickness and the position of the thrombus with respect to the earlier ( $\leq 30$ days) or later (> 30 days) development of a type 2 endoleak [18]. In contrast, in a univariate analysis of 178 patients, Sampaio et al. assigned the thickness of a thrombus at the ostia of the aortic side branches a protective effect with respect to the development of a type 2 endoleak [29]. However, in the present analysis, we were not able to confirm this relationship for the thrombus thickness in the branch region of the IMA $(p=0.5)$ or for the branch thickness in the the branch region of the LAs $(p=0.8)$. Overall, no thrombus-associated parameter of the AAA proved suitable as a predictive factor for the development of a type 2 endoleak in the HRG.

Undoubtedly there is often a persistent IMA typically with retrograde perfusion in a type 2 endoleak after EVAR [20, 22]. However, the number of LAs involved in such an endoleak is usually numerically superior. To what extent do the initial patency of the IMA and its diameter have a prognostic effect on the later development of a type 2 endoleak in the HRG? This relationship has been a subject of controversy in previous studies $[6,18,20,22,29,30]$. In an analysis to identify preoperative predictors, the patency of the IMA was more common in persistent than in transient type 2 endoleaks (81\% versus $43 \%$; p 0.01 ) [20]. In contrast, Sampaio et al. were able to identify a perfused IMA but not its diameter as a predictive factor [29]. An initially perfused IMA did not play a role in the later development of a type 2 endoleak in other studies $[6,18,22,30]$. This coincides with the results of the present study in which the patency of the IMA in the HRG of $92.0 \%$ was higher than the value of $71.3 \%$ in the LRG but was only significantly different in the univariate analysis with $\mathrm{p}=0.003$ but not in the multivariate analysis $(p=0.2)$. This is not surprising because at least one inflow and one outflow vessel must be present for the development of a type 2 endoleak and the IMA can only cause an endoleak in interaction with perfused lumbar arteries. In contrast, both the number and the average diameter of perfused LAs within the aneurysmal sac were prognostically relevant parameters for the later development of a highrisk type 2 endoleak. The probability of the development of an endoleak of the HRG was directly related to the number of perfused LAs and their diameter (see 0 Table 4). These data are in good agreement with the results of other authors [18, 20, 22, 29-31]. Interestingly, there is agreement regarding the critical number of perfused LAs for the development of a persistent endoleak which has been defined as 4 in preceding studies [22, 31]. On average, there were 3.6 \pm 1.2 LAs in the HRG in the present study. An analysis of CT scans acquired directly after EVAR yielded similar results with respect to the development of a type 2 endoleak requiring treatment [32]. This study found significantly more perfused aortic side branches $(4.2 \pm 1.4$ versus $2.9 \pm 1.2$; $\mathrm{p}=0.001$ ) in patients who had to undergo reintervention due to a type 2 endoleak requiring treatment. What is the explanation for this special significance of LAs for the development of an endoleak that is persistent or requires treatment? A type 2 endoleak usually has a nidus that is typically surrounded by a complex angioarchitecture consisting of multiple inflow and outflow vessels [8]. These vessels are usually the IMA and the LAs as aortic side branches in a type 2 endoleak with at least 2 vessels needing to be perfused and then functioning as an inflow and outflow vessel for an endoleak to even be able to develop. Due to the greater anatomical number of LAs, it seems plausible for the LAs to play a more important role than the IMA.

What do these results mean for the endovascular treatment of patients with an AAA? Systematic preoperative embolization of all aortic side branches in the region of the aneurysm reduces the number and size of type 2 endoleaks after EVAR $[33,34]$. On the other hand this means another intervention that is technically demanding, time-consuming, and has a certain risk of complications [35]. The non-critical implementation of preoperative embolization in the clinical 
routine is controversial due to the high rate of spontaneous thrombosis in type 2 endoleaks [36]. However, based on the results of this study, the number and diameter of LAs can be used to identify high-risk patients in whom it seems helpful and justified to perform preoperative embolization (see - Table 4).

\section{Clinical Relevance}

- A number of potentially predictive CT parameters were analyzed in this study to determine their ability to predict the clinical course of type 2 endoleaks after EVAR.

- None of the thrombus-specific parameters proved to be a useful predictor while among anatomical parameters only the aortic diameter showed a trend toward statistical significance.

- The analysis of parameters of the aortic side branches showed that the number and diameter of perfused lumbar arteries can be used to identify patients who are at a high risk for the development of type 2 endoleaks requiring treatment and in whom preoperative embolization seems useful.

\section{References}

1 Endovascular aneurysm repair versus open repair in patients with abdominal aortic aneurysm (EVAR trial 1): randomised controlled trial. Lancet 2005; 365: 2179-2186

2 Parodi JC, Palmaz JC, Barone HD. Transfemoral intraluminal graft implantation for abdominal aortic aneurysms. Annals of vascular surgery 1991; 5: 491 - 499

3 Rhee SJ, Ohki T, Veith FJ et al. Current status of management of type II endoleaks after endovascular repair of abdominal aortic aneurysms. Annals of vascular surgery 2003; 17 : $335-344$

4 Veith FJ, Baum RA, Ohki T et al. Nature and significance of endoleaks and endotension: summary of opinions expressed at an international conference. Journal of vascular surgery: official publication, the Society for Vascular Surgery [and] International Society for Cardiovascular Surgery, North American Chapter 2002; 35: 1029-1035

5 van Marrewijk CJ, Fransen G, Laheij RJ et al. Is a type II endoleak after EVAR a harbinger of risk? Causes and outcome of open conversion and aneurysm rupture during follow-up. European journal of vascular and endovascular surgery: the official journal of the European Society for Vascular Surgery 2004; 27: 128-137

6 Jones JE, Atkins MD, Brewster DC et al. Persistent type 2 endoleak after endovascular repair of abdominal aortic aneurysm is associated with adverse late outcomes. Journal of vascular surgery: official publication, the Society for Vascular Surgery [and] International Society for Cardiovascular Surgery, North American Chapter 2007; 46: 1 -8

7 Fairman RM, Nolte L, Snyder SA et al. Factors predictive of early or late aneurysm sac size change following endovascular repair. Journal of vascular surgery: official publication, the Society for Vascular Surgery [and] International Society for Cardiovascular Surgery, North American Chapter 2006; 43: 649-656

8 Baum RA, Carpenter JP, Stavropoulous SW et al. Diagnosis and management of type 2 endoleaks after endovascular aneurysm repair. Techniques in vascular and interventional radiology 2001; 4: 222-226

9 Abularrage CJ, Patel VI, Conrad MF et al. Improved results using Onyx glue for the treatment of persistent type 2 endoleak after endovascular aneurysm repair. Journal of vascular surgery: official publication, the Society for Vascular Surgery [and] International Society for Cardiovascular Surgery, North American Chapter 2012; 56: 630-636

10 Aziz A, Menias CO, Sanchez LA et al. Outcomes of percutaneous endovascular intervention for type II endoleak with aneurysm expansion. Journal of vascular surgery: official publication, the Society for Vascular Surgery [and] International Society for Cardiovascular Surgery, North American Chapter 2012; 55: 1263 - 1267
11 Nolz R, Teufelsbauer H, Asenbaum $U$ et al. Type II endoleaks after endovascular repair of abdominal aortic aneurysms: fate of the aneurysm sac and neck changes during long-term follow-up. Journal of endovascular therapy: an official journal of the International Society of Endovascular Specialists 2012; 19: 193 - 199

12 Moll FL, Powell JT, Fraedrich $G$ et al. Management of abdominal aortic aneurysms clinical practice guidelines of the European society for vascular surgery. European journal of vascular and endovascular surgery: the official journal of the European Society for Vascular Surgery 2011; 41: S1-S58

13 Chaikof EL, Blankensteijn JD, Harris PL et al. Reporting standards for endovascular aortic aneurysm repair. Journal of vascular surgery: official publication, the Society for Vascular Surgery [and] International Society for Cardiovascular Surgery, North American Chapter 2002; 35 : $1048-1060$

14 Faries PL, Cadot H, Agarwal G et al. Management of endoleak after endovascular aneurysm repair: cuffs, coils, and conversion. Journal of vascular surgery: official publication, the Society for Vascular Surgery [and] International Society for Cardiovascular Surgery, North American Chapter 2003; 37: 1155-1161

15 Schanzer A, Greenberg RK, Hevelone $N$ et al. Predictors of abdominal aortic aneurysm sac enlargement after endovascular repair. Circulation 2011; 123: 2848-2855

16 Axelrod DJ, Lookstein RA, Guller J et al. Inferior mesenteric artery embolization before endovascular aneurysm repair: technique and initial results. JVIR 2004; 15: $1263-1267$

17 Nevala T, Biancari F, Manninen $\mathrm{H}$ et al. Inferior mesenteric artery embolization before endovascular repair of an abdominal aortic aneurysm: effect on type II endoleak and aneurysm shrinkage. JVIR 2010; 21: $181-185$

18 AbuRahma AF, Mousa AY, Campbell JE et al. The relationship of preoperative thrombus load and location to the development of type II endoleak and sac regression. Journal of vascular surgery: official publication, the Society for Vascular Surgery [and] International Society for Cardiovascular Surgery, North American Chapter 2011; 53: 15341541

19 Yeung JJ, Hernandez-Boussard TM, Song TK et al. Preoperative thrombus volume predicts sac regression after endovascular aneurysm repair. Journal of endovascular therapy: an official journal of the International Society of Endovascular Specialists 2009; 16: 380-388

20 Arko FR, Rubin GD, Johnson BL et al. Type-II endoleaks following endovascular AAA repair: preoperative predictors and long-term effects. Journal of endovascular therapy: an official journal of the International Society of Endovascular Specialists 2001; 8: $503-510$

21 Keedy AW, Yeh BM, Kohr JR et al. Evaluation of potential outcome predictors in type II Endoleak: a retrospective study with CT angiography feature analysis. Am J Roentgenol 2011; 197: 234-240

22 Marchiori A, von Ristow A, Guimaraes $M$ et al. Predictive factors for the development of type II endoleaks. Journal of endovascular therapy: an official journal of the International Society of Endovascular Specialists 2011; 18: 299-305

23 Gelfand DV, White GH, Wilson SE. Clinical significance of type II endoleak after endovascular repair of abdominal aortic aneurysm. Annals of vascular surgery 2006; $20: 69-74$

24 Jonker FH, Aruny J, Muhs BE. Management of type II endoleaks: preoperative versus postoperative versus expectant management. Seminars in vascular surgery 2009; 22: $165-171$

25 Karthikesalingam A, Thrumurthy SG, Jackson D et al. Current evidence is insufficient to define an optimal threshold for intervention in isolated type II endoleak after endovascular aneurysm repair. Journal of endovascular therapy: an official journal of the International Society of Endovascular Specialists 2012; 19: 200-208

26 Rayt HS, Sandford RM, Salem M et al. Conservative management of type 2 endoleaks is not associated with increased risk of aneurysm rupture. European journal of vascular and endovascular surgery: the official journal of the European Society for Vascular Surgery 2009; 38: 718 723

27 Timaran $\mathrm{CH}$, Ohki T, Rhee SJ et al. Predicting aneurysm enlargement in patients with persistent type II endoleaks. Journal of vascular surgery: official publication, the Society for Vascular Surgery [and] International Society for Cardiovascular Surgery, North American Chapter 2004; 39: $1157-1162$

28 Higashiura W, Greenberg RK, Katz E et al. Predictive factors, morphologic effects, and proposed treatment paradigm for type II endoleaks 
after repair of infrarenal abdominal aortic aneurysms. JVIR 2007; 18 : 975-981

29 Sampaio SM, Panneton JM, Mozes GI et al. Aneurysm sac thrombus load predicts type II endoleaks after endovascular aneurysm repair. Annals of vascular surgery 2005; 19: 302 - 309

30 Fujita S, Resch TA, Kristmundsson T et al. Impact of intrasac thrombus and a patent inferior mesenteric artery on EVAR outcome. Journal of endovascular therapy: an official journal of the International Society of Endovascular Specialists 2010; 17: 534-539

31 Gorich J, Rilinger N, Sokiranski R et al. Endoleaks after endovascular repair of aortic aneurysm: are they predictable? - Initial results. Radiology $2001 ; 218: 477-480$

32 Dudeck O, Schnapauff D, Herzog L et al. Can Early Computed Tomography Angiography after Endovascular Aortic Aneurysm Repair Predict the Need for Reintervention in Patients with Type II Endoleak? Cardiovascular and interventional radiology 2014; DOI: 10.1007/s00270014-0901-6
33 Alerci M, Giamboni A, Wyttenbach R et al. Endovascular abdominal aneurysm repair and impact of systematic preoperative embolization of collateral arteries: endoleak analysis and long-term follow-up. Journal of endovascular therapy: an official journal of the International Society of Endovascular Specialists 2013; 20: 663-671

34 Pitton MB, Scheschkowski T, Ring $M$ et al. Ten-year follow-up of endovascular aneurysm treatment with Talent stent-grafts. Cardiovascular and interventional radiology 2009; 32: $906-917$

35 Mita T, Arita T, Matsunaga $N$ et al. Complications of endovascular repair for thoracic and abdominal aortic aneurysm: an imaging spectrum. Radiographics: a review publication of the Radiological Society of North America, Inc 2000; 20: 1263 -1278

36 Gould DA, McWilliams R, Edwards RD et al. Aortic side branch embolization before endovascular aneurysm repair: incidence of type II endoleak. JVIR 2001; 12: 337-341 